\title{
La clínica de las letras
}

El clínico profesional acumulará, en su «observación», la cantidad máxima de síntomas, de hechos recogidos. Ninguno le parecerá superfluo, pues -aunque de valor desigual- todos pueden, en un momento dado, contribuir al diagnóstico. En caso necesario será pesado, pero será completo, y la cualidad segunda de su observación es la totalidad.

El artista, por el contrario, que estima cada uno de los hechos observados no en función de un diagnóstico inútil, sino por su belleza plástica, su fuerza expresiva y la intensidad de emoción que de ellos pueda extraer, será menos receptivo. Hará una elección en ese cúmulo de documentos. Este «tiempo» especial de la observación artística y capital, es, a pesar de las apariencias, constante.

$\mathrm{El}$ arte, en efecto, es ante todo selección. Esta selección puede referirse a diferentes categorías de elementos. Así se constituyen las diferentes escuelas. Esta selección fue, por principio, reducida a poca cosa entre los naturalistas franceses; a menos aún entre los escritores alemanes y rusos. El arte es, finalmente, elaboración. En este último período, la observación artística -sea cual fuere su grado de verdad científica- se ha apartado deliberadamente de la observación clínica. No la seguiremos en ese terreno de pura estética, pero teníamos que señalar este último estadio como indispensable y necesario.

$$
\text { * * * * }
$$

La palabra -suele admitirse- es distinta de la idea que encierra. A menudo es superior a ésta. En todo caso, tiene su personalidad y valor científico propios. Es, pues, lícito considerarla por un momento en estado aislado, en una especie de monografía de los términos médicos utilizados por los escritores anteriores. Sabemos de qué triple origen tuvieron que extraer los naturalistas los materiales primeros de sus observaciones. Vamos a comentar ahora el revestimiento verbal con el que envolvieron esos materiales.

Tal estudio podría ser doble: valor estético del vocabulario médico y exactitud de los términos empleados. Este último dato, desdeñable en todos los escritores que no fueron más que «hombres de letras», adquiere aquí una importancia fundamental. En efecto, desde el principio, los naturalistas pretendieron hacer obra de científicos y lo manifestaron en voz bien alta. Consideraremos, pues, el lado puramente literario del estudio para tener en cuenta sólo las cualidades de precisión técnica propias del vocabulario de cada uno de nuestros artistas.

Dejemos primero de lado una posible confusión. Exactitud no es, en materia de lengua médica, sinónimo obligado de neologismo. Una palabra puede ser rigurosamente doctoral sin estar aquejada de una desinencia griega, sin adoptar el 
aspecto de una etiqueta farmacéutica, sin exhalar tufos de hospital. Sin duda, las revistas especializadas se adornan cada vez más con vocablos extraños, compuestos, bastardos, y de una sinonimia desesperadamente complicada.

Por otra parte, la exageración de la terminología técnica es tan nefasta para la literatura médica como opuesta a las tendencias de impersonalidad tan apreciadas por los naturalistas. Algunos de esos verbos técnicos que se esfuerzan por englobar toda una teoría bajo sus sílabas bárbaras, sólo valen en razón de la propia teoría.

Flaubert evitó sensatamente este defecto. Consiguió describir -y en vivouna intoxicación por arsénico, un caso de asfixia crupal, todo ello sin dar la impresión de que supiera que existían modos técnicos de tratar sus cuadros. Sin embargo, por parentesco, tenía acceso a esa documentación verbal que otros han confundido tan desgraciadamente con la documentación verbosa, la verborrea profesional. Deliberadamente, pues, apartó de sus descripciones el término sabio, cargado para él de parcialidad científica, a menudo insuficiente bajo su aspecto pedante, para sustituirlo por el verbo impersonal y verdadero. Describió, no enfermedades, sino enfermos. Se quedó con el síntoma, lo presentó sin preocupase por la etiqueta. En eso fue, verdaderamente clínico.

Sin embargo, múltiples y variados se cuentan en su obra los términos puramente e incluso pomposamente médicos. Pero no están sembrados al azar, siempre aparecen en lugares de erudición ficticia; es decir, cuando la entrada o el discurso de un personaje, él mismo pedante, los excusa, los necesita. Así, no aparecen, en el episódico envenenamiento de Madame Bovary, más que en el momento de la discusión médica que sigue al incidente, cuando Homais, farmacéutico, Canivet, cirujano, y Larivière, médico, se consultan y porfían, doctamente. Están igualmente justificados en los preparativos de Charles Bovary antes de la famosa tenotomía. «Ahora bien, como se trataba de un equino, había que cortar el talón de Aquiles, sin perjuicio de tomarla después con el músculo tibial anterior, para eliminar el varus».

Igual de atinadamente procedieron los hermanos Goncourt. Sólo aventuraron el término técnico cuando el medio, la atmósfera en la que sitúan a sus personajes dolientes, lo pide y lo exige. Entonces, llega la palabra, sin disonancia, exacta y sencilla: «Encefaloide lardaceo del seno derecho», «estepaje» del atáxico. Consiguieron esta mesura, tanto ellos como Flaubert, a costa de verdaderos sufrimientos. Fueron siempre los torturados del verbo y sólo alcanzaron esta admirable sobriedad a fuerza de energía y lucha.

Por el contrario, Daudet, lo consiguió como en broma, y por una ingeniosa intuición de la nota justa: la consulta del Dr Bouchereau (Los reyes en exilio), el diagnóstico entre susurros en la escena final de Jack, donde se percibe, murmurado, «cavernas... estertores sibilantes...», sobre todo esa angustiosa Visita a la Salpêtrière que, por la claridad del vocabulario, podría haber firmado Charcot, todo ello es auténtico, riguroso y justo. 
Con Huysmans se acentúa y se perfecciona la lengua médico-literaria. Abundan en toda su obra los términos especiales -a veces muy finamente especiosos- y dan a su verbo una truculencia y un sabor inigualables. Su empleo sistemático obedece en él, nos parece, a dos procedimientos. O bien hace obra clínica, describe un síntoma, las crisis de ataxia de En la estacada, el cortejo neurasténico de $A$ contrapelo. Y entonces las palabras verdaderas, descriptivas, se acumulan, hasta el punto de que se impone una primera pregunta: ¿hizo Huysmans estudios médicos? «Nunca, nos afirmó él mismo muy amablemente, aunque siempre he tenido curiosidad por las cosas de medicina y me he sentido profundamente atraído por la intensidad de su noción».

O bien emplea términos técnicos como si se tratara de un verdadero procedimiento literario, cuyo mecanismo personal sería el siguiente: en su celo de prodigioso orfebre y obrero del arte, le horroriza ante todo la banalidad de la palabra, expulsa violentamente de su repertorio los clichés reiterados, las figuras repetidas, los términos trasnochados. Se dirige entonces, para suplirlo, a las comparaciones técnicas, a las metáforas científico-literarias, a la jerga de todas las profesiones. Después, como no le bastaba la estricta sinonimia, recurre a la fecunda Analogía, cuyo empleo pudo facilitarle un curioso manual, el Diccionario de las analogías. El estudio detallado de esta «escritura» y de su belleza particular estará más en su lugar en nuestro próximo estudio. Señalaremos sin embargo aquí la nota de pintoresquismo y de verdad histórica que supo dar a cada una de sus metáforas médicas. Del más puro modernismo cuando describe al atáxico en nuestros días o formula el último modo de tratamiento de la neurastenia, se vuelve pertinentemente medieval y usa abundantes y sabrosos arcaísmos si se remonta a épocas pretéritas.

El uso de los términos técnicos no es, pues, más que una indicación de trabajo en Huysmans, novelista. Su proscripción casi total se convierte en Ibsen, dramaturgo, en necesidad de oficio. Sin embargo, Ibsen tenía, como Flaubert, recuerdos médicos personales. Pero el estilo del teatro tiene sus exigencias propias, sus límites estrechos. No se puede decir y hacer decir -dejando de lado cualquier cuestión de censura- todo lo que se escribe: la misma palabra que, percibida con su forma propia y su aspecto tipográfico se perdona o se admira, oída y desfigurada por la acústica artificial de la rampa, resulta enseguida insoportable por inverosímil o pedante. Y ello incluso cuando sale de una boca autorizada. Los papeles de médicos son especialmente delicados de tratar, pues oscilan forzosamente entre la terminología vaga de las mentalidades medias, o el repertorio magistral de la enseñanza técnica. Curel, en su Nuevo ídolo se ha librado muy afortunadamente de ambos defectos escénicos. Brieux, aunque $-\mathrm{y}$ tal vez porque- tratando un tema aún más médico, ha eliminado deliberadamente esas palabras peligrosas $\mathrm{y}$, «aunque muy enterado del tema que trata, no ha adoptado para nada los términos especiales, el estilo particular del tratado de patología»; deliberadamente, decimos, y 
rechazamos la continuación del comentario: «Parece que es casi sin darse cuenta y que las habría empleado si le hubieran venido a la pluma».

Le vinieron a la pluma como le vienen a los labios, abundantes y precisos, esos términos especializados. Los eliminó deliberadamente, ya desde La evasión, cuyo tema, la Herencia fundamental, habría admitido plenamente pasajes documentales y técnicos.

Victor SEgALEN, 1902

(C) Cuatro Ediciones, 2004. El texto está extraído del volumen La vida cóncava (véase: cuatroediciones.com), (C) traducido por Julián Mateo Ballorca.

Los libros de Victor Segalen (1878-1919) han venido recuperándose lentamente, en Francia y luego en España. Lo primero que se rescató fue su magnífica poesía, en una notable Antología (1973), y sus Estelas (1974). Luego se han vertido René Leys (1978 y 2002), novela fundamental sobre China, su escrito El hijo del cielo (1983), el Viaje al país de lo real (1984 y 2002), y su Diario de las islas (2001). Pero la obra de Segalen es amplia, y recorre muy vastos campos de la literatura. Se le considera una figura capital de las letras del siglo XX.

En La vida cóncava se exponen seis muestras suyas que nos presentan a un autor complementario. Además de dos textos breves, autobiográficos, hay el relato singular de dos fugas del mundo occidental, la de Rimbaud y la de Gauguin.

Pero además hay otros dos, extensos, donde critica la idolatría moderna de la Ciencia positivista de su juventud. En primer lugar, el médico Segalen estudia las mezclas de sensaciones (sinestesias) con gran agudeza. En segundo término da cuenta, en La clínica de las letras (de la que se extrae un fragmento notable) de la locura que acecha a los hombres de letras que pretendieron hacer una disección mental de sus congéneres.

Este escrito fue su sintética tesis doctoral. Jean Starobinski ha analizado magistralmente la importancia de este escrito dentro de las relaciones entre literatura y medicina: «Segalen aux confins de la médecine», en Les cliniciens ès lettres, Montpellier, Fata Morgana, 1980. Al escoger un tema de tesis médica, Segalen pensó en el desdoblamiento de la personalidad, en el analogismo sensorial, en la medicina, en el antiguo Egipto o en la histeria y el hipnotismo en la obra wagneriana. Finalmente, se decidió por estudiar La observación médica en los escritores naturalistas, pero luego cambió el título académico por el más sugerente que recogemos. 